\title{
Phenotypic variation of 38 European Ambrosia artemisiifolia populations measured in a common garden experiment
}

\author{
Marion Carmen Leiblein-Wild • \\ Oliver Tackenberg
}

Received: 30 April 2013/Accepted: 23 January 2014/Published online: 11 February 2014

(C) The Author(s) 2014. This article is published with open access at Springerlink.com

\begin{abstract}
The knowledge of phenotypic variation in the European range of the highly allergenic Ambrosia artemisiifolia L. (common ragweed) is not entirely complete, even though it is an invasive species of utmost concern. We hypothesized the prevalence of phenotypic differentiations between common ragweed populations in the introduced range, and we assumed that those differentiations were related to environmental conditions at the points of origin. Using a common garden experiment, we investigated biomass allocation, growth rates, and flowering phenology of 38 European common ragweed populations originating from a major geographical gradient. We observed considerable phenotypic variation in growth parameters and flowering phenology, e.g. mean aboveground biomass varied from 23.3 to $47.3 \mathrm{~g}$ between the populations. We were able to relate most measured traits with environmental parameters prevailing at the points of origin. For example, early growth of ruderal populations was
\end{abstract}

Electronic supplementary material The online version of this article (doi:10.1007/s10530-014-0644-y) contains supplementary material, which is available to authorized users.

M. C. Leiblein-Wild ( $\square)$

Biodiversity and Climate Research Centre (BiK-F),

Senckenberganlage 25, 60325 Frankfurt, Germany

e-mail: mleiblein@senckenberg.de

O. Tackenberg

Institute of Ecology, Evolution and Diversity, Goethe

University Frankfurt, Max-von-Laue-Str. 13, 60438

Frankfurt, Germany highly correlated with temperature and precipitation at the point of origin. Late growth and flowering phenology were highly correlated with latitude, i.e. individuals from northern populations grew smaller and flowered and dispersed their pollen and seeds up to 5 weeks earlier than individuals from southern populations. We also found a longitudinal gradient in flowering phenology which has not yet been described. The existence of such a high variability in the introduced range may facilitate further range expansion. We suggest that the correlation with environmental variables rests upon genetic variation possibly due to adaptations to the respective environment. To clarify if such adaptation results from multiple events of introduction or as evolutionary response after introduction, genetic investigations are needed.

Keywords Adaptation - Common ragweed · Europe $\cdot$ Flowering phenology $\cdot$ Growth rate . Invasive species $\cdot$ Neobiota

\section{Introduction}

Ambrosia artemisiifolia L. (common ragweed) is one of the most dangerous invasive alien plant species in Europe due to its strongly allergenic pollen and due to its successful and continuing invasion of central and northern Europe (Alberternst et al. 2006; Otto et al. 2008). Its potential range in Europe is expected to increase with climate change (Cunze et al. 2013). In 
this work, we investigate phenotypic variation of common ragweed populations that originate from a major geographical gradient in the invasive range of Europe.

Clinal variation, i.e. phenotypic variation over a distributional range of a species which is correlated with environmental parameters, is characteristic for many species (e.g. Becker et al. 2006; Joshi et al. 2001). It typically results from environmental heterogeneity and is often correlated with latitudinal or altitudinal gradients (Bruelheide and Heinemeyer 2002; Chun et al. 2011; Weber and Schmid 1998). The amount of phenotypic variation between populations may help to estimate further range expansion and to understand evolutionary trends (Hierro et al. 2009).

For A. artemisiifolia, the knowledge on phenotypic variation in Europe is still incomplete, as most studies only investigate populations from one or few points of origin. Their results yield an important contribution for understanding aspects of the species' ecology and range dynamics, but may also be limited in their explanatory power due to the high variability of the species (Fumanal et al. 2007; Paquin and Aarssen 2004). In the native range in North America, the existence of different 'ecotypes' which vary in height and the time of flowering along a latitudinal gradient has been demonstrated (Dickerson and Sweet 1971). Studies on phenotypic variation in Europe mainly refer to some French A. artemisiifolia populations (Fumanal 2007; Hodgins and Rieseberg 2011). However, studies which investigate phenotypic variation of populations all over the current range of distribution in Europe are missing. Furthermore, relations of phenological traits to factors other than latitude have not been analyzed, although the potential geographical range of many plant species is primarily determined by temperature and precipitation (Reznik 2009).

In temperate latitudes, changes in the length of day (LOD) act as reliable cues of oncoming changes in seasonality and temperature (Bradshaw et al. 2004). Especially annual plant species such as A. artemisiifolia strongly depend on the appropriate timing of development and reproduction to persist at a site (Thomas and Vince-Prue 1997). Thus, as in many other plant species (Van Dijk and Hautekèete 2007), the flowering period is regulated by the seasonal LOD in A. artemisiifolia (Allard 1945). Recent studies emphasize the importance of LOD affecting range expansion of introduced species (Saikkonen et al.
2012). However, to our knowledge it has not yet been tested, whether A. artemisiifolia populations from different points of origin differ in their LOD requirements.

In Europe, A. artemisiifolia mainly grows as weed in crops or in disturbed habitats (Kazinczi et al. 2008). The environmental conditions between these sites may differ considerably, e.g. soils at agricultural sites are usually deep and contain more nitrogen than ruderal sites, due to fertilization. Nitrogen has a positive effect on biomass allocation and seed production of $A$. artemisiifolia (Leskovsek et al. 2012) and may influence reproductive traits of the offspring indirectly via maternal effects.

The purpose of our study is to fill the gap of knowledge on phenotypic variation of A. artemisiifolia populations across the current introduced range in Europe, and to analyze whether differences in growth and flowering traits can be related to differences in the environment at the respective point of origin. We hypothesize that (1) variation in growth rates, biomass accumulation and flowering phenology exists in A. artemisiifolia populations from different points of origin within Europe, (2) the differences between populations are related to climatic parameters, specifically temperature, precipitation and length of day (LOD) at the point of origin, (3) populations from agricultural sites show increased seed mass, growth rates and biomass accumulation due to benefits from increased nitrogen availability at the maternal environment, and (4) the timing of flowering phenology which is regulated mainly by the LOD does not differ between populations from different habitat types.

\section{Materials and methods}

\section{Species description}

Ambrosia artemisiifolia L. (Asteraceae) is an annual plant species native to North America where it grows in open grasslands or as a competitive weed in crops. In Europe, A. artemisiifolia mainly grows in disturbed, open habitats (ruderal sites) or as a weed in crops (agricultural sites, Kazinczi et al. 2008). The species is monoecious with staminate flowers arranged in leafless racemes at the end of shoots and branches, and pistillate flowers in the shoulders of the upper leaves 
Table 1 Provenances and biogeographical characteristics of 38 European A. artemisiifolia populations

\begin{tabular}{|c|c|c|c|c|c|c|c|c|}
\hline Lat $\left({ }^{\circ} \mathrm{N}\right)$ & Lon $\left({ }^{\circ} \mathrm{E}\right)$ & Country code & Region & Habitat & PopID & Prec $(\mathrm{mm})$ & Temp $\left({ }^{\circ} \mathrm{C}\right)$ & LOD (h) \\
\hline 53.550 & 10.000 & GER & Hamburg & $\mathrm{R}$ & 28 & 76.0 & 16.5 & 16.04 \\
\hline 51.767 & 14.469 & GER & Cottbus & $\mathrm{R}$ & 33 & 64.3 & 18.1 & 15.77 \\
\hline 51.754 & 13.963 & GER & Calau & A & 31 & 64.7 & 18.0 & 15.76 \\
\hline 51.754 & 13.973 & GER & Calau & A & 32 & 64.7 & 18.0 & 15.76 \\
\hline 51.188 & 6.793 & GER & Düsseldorf & $\mathrm{R}$ & 38 & 77.7 & 17.8 & 15.68 \\
\hline 50.091 & 8.553 & GER & Höchst & $\mathrm{R}$ & 29 & 64.3 & 18.0 & 15.53 \\
\hline 50.087 & 14.472 & $\mathrm{CZ}$ & Prague & $\mathrm{R}$ & 34 & 69.0 & 17.8 & 15.53 \\
\hline 49.794 & 8.606 & GER & Pfungstadt & A & 30 & 67.3 & 18.2 & 15.49 \\
\hline 49.701 & 9.274 & GER & Miltenberg & $\mathrm{R}$ & 0 & 76.3 & 17.3 & 15.48 \\
\hline 49.54 & 8.465 & GER & Mannheim & $\mathrm{R}$ & 21 & 69.0 & 18.4 & 15.46 \\
\hline 49.534 & 8.466 & GER & Mannheim & $\mathrm{R}$ & 20 & 69.0 & 18.4 & 15.46 \\
\hline 49.261 & 8.591 & GER & St.Leon-Rot & A & 19 & 73.0 & 18.6 & 15.42 \\
\hline 49.107 & 8.453 & GER & Karlsruhe & $\mathrm{R}$ & 18 & 74.3 & 18.7 & 15.41 \\
\hline 49.044 & 8.393 & GER & Karlsruhe & $\mathrm{R}$ & 17 & 74.3 & 18.8 & 15.40 \\
\hline 48.995 & 8.400 & GER & Karlsruhe & $\mathrm{R}$ & 16 & 75.0 & 18.8 & 15.39 \\
\hline 47.671 & 19.672 & $\mathrm{H}$ & Hatvan & $\mathrm{R}$ & 24 & 57.0 & 20.0 & 15.23 \\
\hline 47.668 & 9.164 & GER & Konstanz & $\mathrm{R}$ & 36 & 110.7 & 17.9 & 15.23 \\
\hline 47.632 & 19.449 & $\mathrm{H}$ & Bag & $\mathrm{R}$ & 23 & 57.3 & 20.0 & 15.22 \\
\hline 47.463 & 19.231 & $\mathrm{H}$ & Budapest & $\mathrm{R}$ & 22 & 57.0 & 20.3 & 15.20 \\
\hline 47.324 & 5.127 & $\mathrm{~F}$ & Quetigny & A & 1 & 66.7 & 18.7 & 15.19 \\
\hline 47.217 & 5.529 & $\mathrm{~F}$ & Longeault & A & 2 & 76.7 & 18.7 & 15.17 \\
\hline 47.212 & 19.389 & $\mathrm{H}$ & Újhartyán & A & 25 & 55.7 & 20.4 & 15.17 \\
\hline 47.190 & 5.257 & $\mathrm{~F}$ & Tart-l'Abbaye & A & 3 & 69.3 & 18.9 & 15.17 \\
\hline 47.183 & 5.255 & $\mathrm{~F}$ & Tart-l'Abbaye & A & 4 & 69.3 & 18.9 & 15.17 \\
\hline 46.887 & 19.539 & $\mathrm{H}$ & Ballószög & A & 26 & 56.3 & 20.3 & 15.14 \\
\hline 46.883 & 19.557 & $\mathrm{H}$ & Ballószög & A & 27 & 56.3 & 20.3 & 15.14 \\
\hline 46.769 & 17.248 & $\mathrm{H}$ & Keszthely & A & 37 & 75.0 & 19.9 & 15.12 \\
\hline 45.781 & 5.038 & $\mathrm{~F}$ & Meyzieu & A & 7 & 70.0 & 19.7 & 15.01 \\
\hline 45.771 & 4.988 & $\mathrm{~F}$ & Meyzieu & $\mathrm{R}$ & 6 & 69.7 & 19.7 & 15.01 \\
\hline 45.766 & 5.067 & $\mathrm{~F}$ & Pusignan & A & 8 & 70.7 & 19.7 & 15.01 \\
\hline 45.746 & 5.073 & $\mathrm{~F}$ & Pusignan & $\mathrm{R}$ & 5 & 71.3 & 19.6 & 15.01 \\
\hline 45.049 & 4.984 & $\mathrm{~F}$ & Granges-les-Beaumont & $\mathrm{R}$ & 9 & 63.7 & 20.2 & 14.93 \\
\hline 45.046 & 4.984 & $\mathrm{~F}$ & Granges-les-Beaumont & A & 10 & 63.7 & 20.2 & 14.93 \\
\hline 45.038 & 5.014 & $\mathrm{~F}$ & Romans-sur-Isère & $\mathrm{R}$ & 11 & 62.7 & 20.3 & 14.93 \\
\hline 44.233 & 4.277 & $\mathrm{~F}$ & Rivières & A & 15 & 46.3 & 21.2 & 14.85 \\
\hline 44.229 & 4.318 & $\mathrm{~F}$ & Tharaux & $\mathrm{R}$ & 14 & 48.7 & 20.5 & 14.85 \\
\hline 44.032 & 4.531 & $\mathrm{~F}$ & Saint-Hippolyte-de-Montaigu & A & 13 & 43.7 & 21.0 & 14.83 \\
\hline 44.013 & 4.587 & $\mathrm{~F}$ & Valliguières & A & 12 & 44.0 & 20.8 & 14.82 \\
\hline
\end{tabular}

Lat latitude, Lon longitude; Habitat: $R$ ruderal population, $A$ agricultural population, PopID identification code for each population, Prec mean precipitation between June and August, Temp mean temperature between June and August calculated from monthly data (worldclim.org, Hijmans et al. 2005), LOD mean length of day from June to August (http://www.jgiesen.de/astro/astroJS/ rsTableWorld/index.htm)

and on the bottom of male racemes (Brandes and Nitzsche 2006). The wind-dispersed pollen of $A$. artemisiifolia is a strong allergen and may cause hay fever and dermatitis (Taramarcaz et al. 2005). A. artemisiifolia reproduces via seeds which are viable up to 39 years (Toole and Brown 1946) and need a 


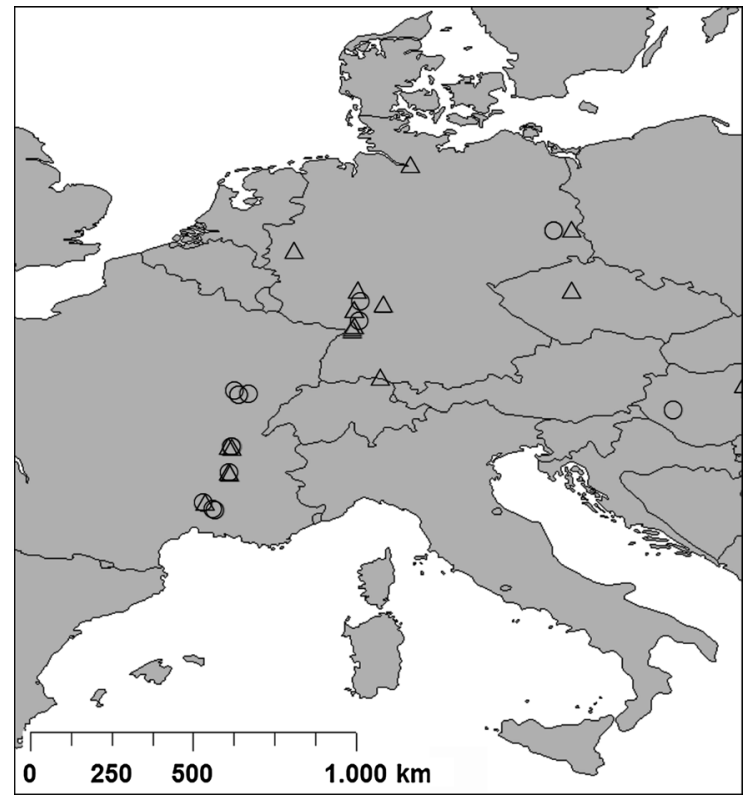

Fig. 1 Points of origin of 38 A. artemisiifolia populations sampled along major latitudinal and longitudinal gradients in Europe and used in the common garden experiment; circles $=$ agricultural sites, triangles $=$ ruderal sites

stratification to break dormancy, normally supplied by winter temperature conditions.

\section{Seed collection and experimental design}

We measured the phenotypic development of vegetative and generative life history traits of A. artemisiifolia populations from different European provenances in a common garden experiment. In 2008, seeds from 38 European sites were collected (Table 1). For each population we collected seeds from 20 to 30 individuals to get a representative subset. The geographical range was from $53.6^{\circ} \mathrm{N}$ (Hamburg, Germany) to $44.0^{\circ} \mathrm{N}$ latitude (Valliguières, France) and from $4.3^{\circ} \mathrm{E}$ (Rivières, France) to $19.7^{\circ} \mathrm{E}$ longitude (Hatvan, Hungary, Table 1; Fig. 1). Sampled habitats were classified as ruderal or agricultural sites, populations from other habitats were not sampled. According to Willemsen (1975), the seeds were stored at ca. $3{ }^{\circ} \mathrm{C}$ in a fridge for at least 3 months before starting the experiment to break dormancy.

In March 2009 around 60 seeds per population were germinated outdoors in Frankfurt am Main (Germany, $\left.50.1^{\circ} \mathrm{N}, 8.7^{\circ} \mathrm{E}\right)$ under natural temperature conditions (mean temperature March: $6.1{ }^{\circ} \mathrm{C}$ ). At the developmental stage of two or four leaves, 19 randomly chosen seedlings per population were transplanted into pots (2 1) with fertilized sand (slow release fertilizer: Osmocote Exact Standard 5-6 M $\left(15 \% \mathrm{~N}, 9 \% \mathrm{P}_{2} \mathrm{O}_{5}, 12 \% \mathrm{~K}_{2} \mathrm{O}\right) ; 6 \mathrm{~g} / \mathrm{l}$ sand). The pots were placed outdoors in a randomized way. To ensure sufficient soil moisture content, the pots were watered daily throughout the experiment which lasted from April 15, 2009 to October 12, 2009 when the individuals had finished their life cycle.

\section{Aboveground biomass (ABM)}

To reduce the number of required individuals, we determined aboveground dry biomass (ABM) with a non-destructive approach which was calibrated by some destructive measurements (Tackenberg 2007): At $6,10,12,14,16,18$ and 22 weeks after the beginning of the experiment [Julian days (JD) 147, 175, 189, 203, 217, 231, and 259], we took digital photos of five individuals per population (Nikon D90, Tokyo, Japan). On the first two measurement dates the photos were taken from the top due to low plant height. From the third measurement date onwards we took vertical silhouette photos in front of a bluish background. A red scale of defined size was located next to the plant on each photo.

After taking the photos, two individuals per population were harvested at each date. Aboveground dry biomass (ABM) was determined after drying at $65^{\circ} \mathrm{C}$ for at least 7 days to a constant weight. Based on the measured ABM values and the photos of these individuals, we developed two linear models (one for the photos taken from the top and the other for the silhouettes) describing the correlation between the measured ABM values and the projection area displayed on the photos. For the analysis of the photos we used ImageJ (ImageJ 1.44, http://rsbweb.nih.gov/ij/) and a macro for semiautomatic analysis. During the process of our image analysis, the red scale is first separated from the background and used to calculate the pixel $\mathrm{mm}^{-2}$ ratio of the photo. Second, the plant individual is separated from the background. Third, the number of pixels of the plant is counted and their projection area $\left(\mathrm{mm}^{2}\right)$ is calculated as a quotient of the number of pixels and the ratio (number of pixels $\mathrm{mm}^{-2}$ ).

To normalize the skewed data, the projection area and the ABM values were log-transformed. Based on this data we developed two linear models, one for the 
pictures taken from the top [log (projection area) $=0.989 * \log (\mathrm{ABM})-4.392, \quad \mathrm{R}^{2}=0.92$, $P<0.001]$, the second for silhouette photos [log $($ projection area $)=1.076 * \log (\mathrm{ABM})-4.156$, $\left.\mathrm{R}^{2}=0.96, P<0.001\right]$. Each model was fitted with $70 \%$ of the values and validated with the remaining $30 \%$ of values (the model for silhouette photos and its validation is shown as an example in the Electronic Supplementary Material (ESM, Fig. A1). Using these two models, we calculated dry aboveground biomass values of five individuals for each population $(\mathrm{N}=38)$ and date $(\mathrm{N}=7)$ based on their projection area, respectively. For the maximum aboveground biomass $\left(\mathrm{ABM}_{\mathrm{Max}}\right)$, we defined the highest mean $A B M$ value of a population during the seven measurement dates, irrespective of the absolute date.

\section{Absolute growth rates (AGR)}

We calculated absolute growth rates (AGR) from the aboveground biomass values of five individuals per population in three time intervals: (1) $A_{G} R_{J u n}$ describes the early development of seedlings (between May 27 and June 24, 2009), (2) AGR $_{\text {Jul }}$ represents the growth of partially blooming middle-aged plants (between June 24 and July 22, 2009), (3) AGR Aug represents adult, completely flowering plants (between July 22 and August 19, 2009). For each population, the AGR values of five individuals were averaged and used in further analyses.

\section{Flowering dates}

We conducted weekly observations on the floral stage of common ragweed. Hereby, the developmental stage of five or six randomly chosen individuals of each population was assessed weekly between July 02, 2009 and October 12, 2009. For the assessment, we chose the floral stage which was representative for most blossoms of the whole plant individual.

We defined the following five stages each individual could achieve: (1) initiation of staminate flowers (STA), i.e. the appearance of staminate buds on the individual, (2) initiation of pollen release $\left(\mathrm{PR}_{\mathrm{ini}}\right)$, i.e. $>50 \%$ of staminate flowers of the individual are open, (3) end of pollen release $\left(\mathrm{PR}_{\mathrm{end}}\right)$, i.e. $>50 \%$ of staminate flowers of the individual are withered, (4) initiation of pistillate flowers (PIS), i.e. appearance of pistillate flowers on the individual, and (5) dissemination (DIS), i.e. $>50 \%$ of seeds of the individual are thrown off.

To analyze differences in the floral development between the 38 populations, we plotted the proportion of individuals per population which had entered the respective floral stage (1) to (5) against the date of observation. Using linear interpolation, we determined the Julian day (JD) at which each floral stage was reached by a threshold of $50 \%$ of individuals for each population (ESM, Fig. A2). This JD was defined as the respective flowering date (FD) for each population and was used for further analysis.

Climatic and biogeographical variables

Our data on temperature and precipitation, monthly mean values of current conditions (1950-2000), were derived from the WorldClim Global Climate Database (Hijmans et al. 2005) with a spatial resolution of $1 \mathrm{~km}^{2}$. LOD for each population was calculated with an open source software tool (http://www.jgiesen.de/ astro/astroJS/rsTableWorld/index.htm). We calculated mean LOD during June to August based on the geographical coordinates of the populations. Since we considered temperature, precipitation, and length of day (LOD) during the main growing season as most important, we used the mean averages of the months June to August as explanatory variables.

Seed mass

The seed mass of all sampled populations was determined. To determine average seed mass we took five replicates of 50 randomly chosen seeds per population. Seeds were weighed (CPA225D, Sartorius, Germany) and mean mass was per seed calculated for each population.

\section{Statistics}

We analyzed correlations of growth traits with geographical and climatic variables prevailing at the points of origin. For these analyses we calculated mean values from five individuals per population for $\mathrm{AGR}_{\mathrm{Jun}}, \mathrm{AGR}_{\mathrm{Jul}}, \mathrm{AGR}_{\mathrm{Aug}}$, and $\mathrm{ABM}_{\mathrm{Max}}$. To analyze the Spearman rank correlation-coefficients of floral dates with climatic variables, the Julian day of each population (which was calculated with an average of 
Fig. 2 Growth of $A$. artemisiifolia populations cultivated in a common garden experiment. a Aboveground biomass (ABM) for seven harvest dates; JD = Julian day, $\mathrm{N}=190$ for each date. b Absolute growth rate in August $\left(\mathrm{AGR}_{\mathrm{Aug}}\right)$ in relation to the latitudinal origin (Spearman $\rho=-0.323$, $P=0.048$ ); data points show mean values of five individuals per population $(\mathrm{N}=38)$

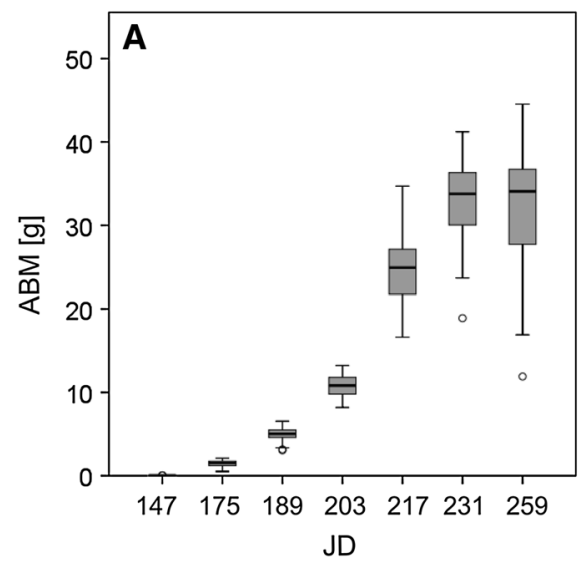

five individuals) was correlated with the explaining variables. To explore possible differences of population mean averages for each single response variable $\left(\mathrm{AGR}_{\mathrm{Jun}}, \mathrm{AGR}_{\mathrm{Jul}}, \mathrm{AGR}_{\mathrm{Aug}}, \mathrm{ABM}_{\mathrm{max}}\right.$, all floral dates) between ruderal and agricultural populations, we used the Mann-Whitney $U$ test. When significant differences were not found, the values of both habitat types were put together during further analyses. We analyzed the response variables for each habitat type separately when differences were significant. All test differences were considered significant at $P<0.05$. All statistics were computed using R (Version 2.11.1, R Development Core Team, 2011) or SPSS 20 (SPSS Inc, Chicago, IL, USA).

\section{Results}

All individuals which grew from March till October 2009 ( $N=160)$ flowered and produced seeds under the local experimental conditions. The development of aboveground biomass over time is presented in Fig. 2a. We found significant correlations of early growth, late growth and reproductive phenology with climatic and geographical parameters, which are presented in succession in the following.

Early growth of ruderal and agricultural populations

From the mid of April to the end of June (JD 105-181) the plant individuals grew slowly with absolute growth rates $\left(\mathrm{AGR}_{\mathrm{Jun}}\right)$ of $7.0-29.3 \mathrm{mg} \mathrm{day}^{-1}$ (Table 2). Between the end of June and the end of July (JD
212) $\mathrm{AGR}_{\mathrm{Jul}}$ increased to $81.9-132.3 \mathrm{mg} \mathrm{day}^{-1}$ (Table 2). As $\mathrm{AGR}_{\mathrm{Jun}}$ and $\mathrm{AGR}_{\mathrm{Jul}}$ was significantly higher in populations originating from agricultural sites (Mann-Whitney $U$ test, $P=0.002$, ESM Table A1) we examined the possible correlations with biogeographical variables for each habitat type separately. For individuals from ruderal sites, $\mathrm{AGR}_{\mathrm{Jun}}$ and $\mathrm{AGR}_{\mathrm{Jul}}$ were very negatively correlated with precipitation at the point of origin (Table 2). AGR Jun was positively correlated with temperature for ruderal populations (Table 2). In contrast, no correlation between $\mathrm{AGR}_{\mathrm{Jun}}, \mathrm{AGR}_{\mathrm{Jul}}$ and latitude and longitude was found for ruderal populations (Table 2). For individuals from agricultural sites, no correlation of $\mathrm{AGR}_{\mathrm{Jun}}$ and $\mathrm{AGR}_{\mathrm{Jul}}$ with any of the explaining variables was found (Table 2). Seed mass did not differ between populations from agricultural $($ mean $=5.33 \mathrm{mg})$ and ruderal $($ mean $=5.94 \mathrm{mg})$ habitats (Mann-Whitney $U$ test, $P=0.411$ ).

Late growth

$\mathrm{AGR}_{\text {Aug }}$ varied from 147.7 to $322.1 \mathrm{mg} \mathrm{day}^{-1}$ (Table 2). As $\mathrm{AGR}_{\text {Aug }}$ and $\mathrm{ABM}_{\mathrm{Max}}$ did not differ between populations from different habitat types (Mann-Whitney $U$ test, $P>0.05$, ESM Table A1), the measured data of these variables were analyzed together. $A_{G R}$ Aug was negatively correlated with LOD, respectively latitude during late growth (Fig. 2b), whereas no correlation between $\mathrm{AGR}_{\text {Aug }}$ and precipitation or temperature was observed (Table 2).

The maximal aboveground biomass $\left(\mathrm{ABM}_{\mathrm{Max}}\right)$ was $36.9 \pm 5.9 \mathrm{~g}$ (mean $\pm \mathrm{SD}$ ) and was negatively correlated with latitude, respectively LOD, and highly 
Table 2 Measured values of growth traits and floral dates and their correlation (Spearman rank correlation-coefficients) with environmental parameters of the points of origin

\begin{tabular}{|c|c|c|c|c|c|c|c|c|}
\hline & \multicolumn{3}{|c|}{ Measured values } & \multicolumn{5}{|c|}{ Correlation with environmental parameters } \\
\hline & Mean $\pm \mathrm{SD}$ & Min & Max & Lat & Lon & Prec & Temp & LOD \\
\hline \multicolumn{9}{|l|}{ Growth traits } \\
\hline $\operatorname{AGR}_{J u n}(\mathrm{R})\left(\mathrm{mg} \mathrm{d}^{-1}\right)$ & $18.4 \pm 4.0$ & 11.6 & 26.5 & -0.307 & 0.159 & $-0.689 * * *$ & $0.540 *$ & -0.317 \\
\hline $\operatorname{AGR}_{J u n}(\mathrm{~A})\left(\mathrm{mg} \mathrm{d}^{-1}\right)$ & $22.8 \pm 4.8$ & 7.0 & 29.3 & 0.157 & 0.283 & -0.161 & -0.002 & 0.157 \\
\hline $\mathrm{AGR}_{\mathrm{Jul}}(\mathrm{R})\left(\mathrm{mg} \mathrm{d}^{-1}\right)$ & $100.7 \pm 12.1$ & 81.9 & 124.5 & -0.027 & 0.323 & $-0.575^{* *}$ & 0.205 & -0.039 \\
\hline $\operatorname{AGR}_{\text {Jul }}(\mathrm{A})\left(\mathrm{mg} \mathrm{d}^{-1}\right)$ & $114.8 \pm 12.8$ & 85.8 & 132.3 & 0.025 & 0.183 & -0.283 & 0.142 & 0.031 \\
\hline $\operatorname{AGR}_{\text {Aug }}\left(\mathrm{mg} \mathrm{d}^{-1}\right)$ & $259.0 \pm 41.7$ & 147.7 & 322.1 & $-0.323 *$ & 0.015 & 0.007 & 0.254 & $-0.324 *$ \\
\hline $\mathrm{ABM}_{\mathrm{Max}}(\mathrm{g})$ & $36.9 \pm 5.9$ & 23.3 & 47.3 & $-0.567 * * *$ & -0.227 & -0.174 & $0.506 * *$ & $-0.568 * * *$ \\
\hline \multicolumn{9}{|l|}{ Floral dates } \\
\hline STA (JD) & $207 \pm 7$ & 183 & 216 & $-0.403 *$ & $-0.571 * * *$ & 0.052 & 0.171 & $-0.404 *$ \\
\hline $\mathrm{PR}_{\text {ini }}(\mathrm{JD})$ & $233 \pm 10$ & 196 & 244 & $-0.633 * * *$ & $-0.665 * * *$ & -0.069 & $0.394 *$ & $-0.634 * * *$ \\
\hline $\mathrm{PR}_{\mathrm{end}}(\mathrm{JD})$ & $271 \pm 6$ & 258 & 280 & $-0.660 * * *$ & $-0.450 * *$ & -0.234 & $0.557 * * *$ & $-0.662 * * *$ \\
\hline $\mathrm{PR}_{\text {length }}$ (number of days) & $38 \pm 7$ & 29 & 62 & 0.162 & $0.351 *$ & -0.124 & 0.024 & 0.159 \\
\hline PIS (JD) & $226 \pm 7$ & 205 & 237 & $-0.661 * * *$ & $0.628 * * *$ & -0.176 & $0.517 * * *$ & $-0.661 * * *$ \\
\hline DIS (JD) & $265 \pm 7$ & 248 & 275 & $-0.699 * * *$ & $0.467 * *$ & -0.228 & $0.569 * * *$ & $-0.700 * * *$ \\
\hline
\end{tabular}

$A G R_{J u n}-A G R_{\text {Aug }}$ absolute growth rates as classified in "Materials and methods", $R$ ruderal population, $A$ agricultural population, $A B M_{\text {max }}$ maximum aboveground biomass, $S T A$ initiation of staminate flowers, $P R_{\text {ini }}$ initiation of pollen release, $P R_{\text {end }}$ end of pollen release, $P R_{\text {length }}$ length of pollen release, $P I S$ initiation of pistillate flowers, DIS dissemination, Min Minimum, Max Maximum, Lat latitude, Lon longitude, Prec mean precipitation during June to August, Temp mean temperature during June to August calculated from monthly data derived from worldclim.org (Hijmans et al. 2005), LOD mean length of day during June to August (http://www. jgiesen.de/astro/astroJS/rsTableWorld/index.htm). Values in bold indicate significant correlations $(P<0.05)$

*** $P<0.001$, ** $P<0.01$, * $P<0.05$

positively correlated with temperature at the point of origin (Table 2). According to the $\mathrm{BBCH}$ scale the developmental stage when $\mathrm{ABM}_{\max }$ was achieved was the principal growth stage 8 for weed species (ripening or maturity of fruit and seeds, BBCH Monograph 2001).

Flowering phenology

The floral development of 160 A. artemisiifolia individuals over time is presented in Fig. 3. First staminate buds arose by the end of June (JD 181, LOD Frankfurt $=16.34 \mathrm{~h}$ ) in $4 \%$ of individuals (Fig. 3a). By the middle of July (JD 197, LOD Frankfurt $=15.93 \mathrm{~h}$ ), $10 \%$ of individuals had initiated staminate flowers. By the end of July (JD 211, LOD Frankfurt $=15.33 \mathrm{~h}$ ), $70 \%$ of individuals had developed staminate flowers, which were opened in around $10 \%$ (Fig. 3a). First pollen release was observed on 16 July (JD 197, LOD $_{\text {Frankfurt }}=15.93 \mathrm{~h}$ (Fig. 3a). Between 21 Aug. and
09 Sep. (JD 233-252, LOD $_{\text {Frankfurt }}=14.15$ and $13.00 \mathrm{~h}$, respectively) $90 \%$ of all individuals released pollen, thereafter pollen release decreased since the first individuals started withering. Nevertheless, pollen release continued until the beginning of October $(\mathrm{JD}=276)$ in a clearly reduced number of individuals (Fig. 3a). First scattering of seeds was observed on JD $240\left(\mathrm{LOD}_{\text {Frankfurt }}=13.74 \mathrm{~h}\right)$ in $0.6 \%$ of individuals, by the middle of October (JD $=276$, LOD $_{\text {Frank- }}$ furt $=11.52 \mathrm{~h}) 92 \%$ of individuals had scattered seeds (Fig. 3b).

When comparing the population levels we found a high level of intraspecific variation for all floral dates. For example, the mean length of pollen release was 38 days, but varied considerably from 29 (Pop 36) to 62 days (Pop 31) between the single populations; the initiation of staminate flowers varied from JD 183 (Pop 32) to JD 216 (Pop 15). For mean, minimum and maximum values for all floral dates see Table 2. As the flowering dates did not differ between populations 
Fig. 3 Floral development of $A$. artemisiifolia during the year: proportion of individuals (from 38 European sites and grown in a common garden) in different flowering phases. a Staminate flowering and pollen release. b Pistillate flowering and dissemination. JD = Julian day, $\mathrm{N}=160$

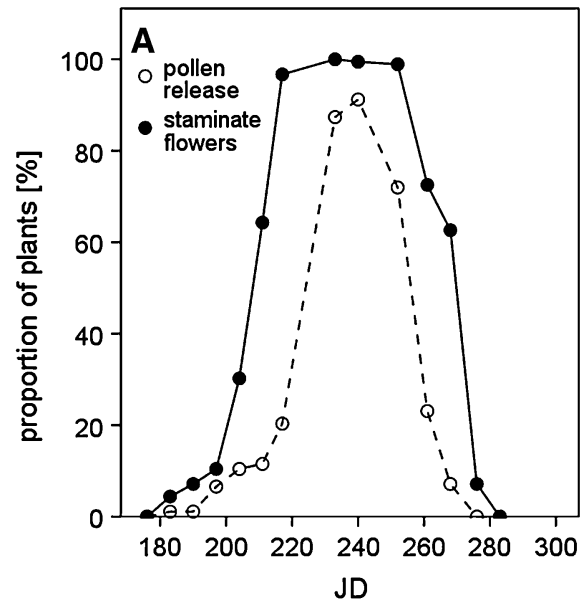

from ruderal and agricultural habitats (Mann-Whitney $U$ test, $P>0.05$, ESM, Table A1) they were put together during correlation analysis.

All flowering dates (except for the length of pollen release) were very negatively correlated with latitude (Table 2; Fig. 4), i.e. northern populations started staminate flowering, pistillate flowering, pollen release and dissemination earlier than populations from the South (Fig. 4). Floral dates were also correlated with longitude (Table 2). The more eastern the provenance of a population was, the earlier staminate flowering phases occurred. Conversely, eastern populations initiated pistillate flowers and dissemination later than western ones (Table 2). Accordingly, $\mathrm{PR}_{\text {length }}$ was positively correlated with longitude. We also observed a highly significant positive correlation of most measured floral dates (except $\mathrm{PR}_{\text {length }}$ and STA) with temperature at the point of origin (Table 2). Precipitation of the original site was not correlated with any of the parameters characterizing A. artemisiifolia's floral development.

\section{Discussion}

We found evidence for the existence of considerable phenotypic variation in growth rates, biomass accumulation and flowering phenology across 38 European A. artemisiifolia populations sampled along a major geographical gradient. Similar phenotypic variation was found in other invasive species (Kollmann and Banuelos 2004; Montague et al. 2008; Weber and Schmid 1998). Accordingly, a high variability between common ragweed populations in the field has been observed, such as size at maturity, which can range from several centimetres up to $2.5 \mathrm{~m}$ height (Bassett and Crompton 1975, own observations). Time of flowering may also vary strongly between populations (Dickerson and Sweet 1971; Hodgins and Rieseberg 2011). Phenotypic variation between populations may occur in terms of clines especially along large latitudinal or other environmental gradients (Erfmeier et al. 2013) which we also observed in this study. Whether this variability results from phenotypic plasticity as a response to environmental conditions at the respective site of origin or from genetic adaptation has not yet been evaluated. Both, high phenotypic plasticity (Parker et al. 2003; Richards et al. 2006) and local adaptation (Dlugosch and Parker 2008; Lee 2002; Whitney and Gabler 2008), are seen as key characteristics for the successful coping of invasive species in new environments.

In our experiment, we found a high level of intraspecific variation for many traits in the European A. artemisiifolia populations. Since all individuals from different populations were grown in the same common garden and under the same experimental conditions, it is reasonable enough to conclude that the observed differences may result from genetic variation and to some extent from maternal effects, especially for early developmental stages. The prevalence of such high phenotypic variation and the prevalent close relation to environmental factors at the point of origin points to a high selective pressure on growth characteristics and flowering phenology in common ragweed. In contrast, for other common ragweed life 

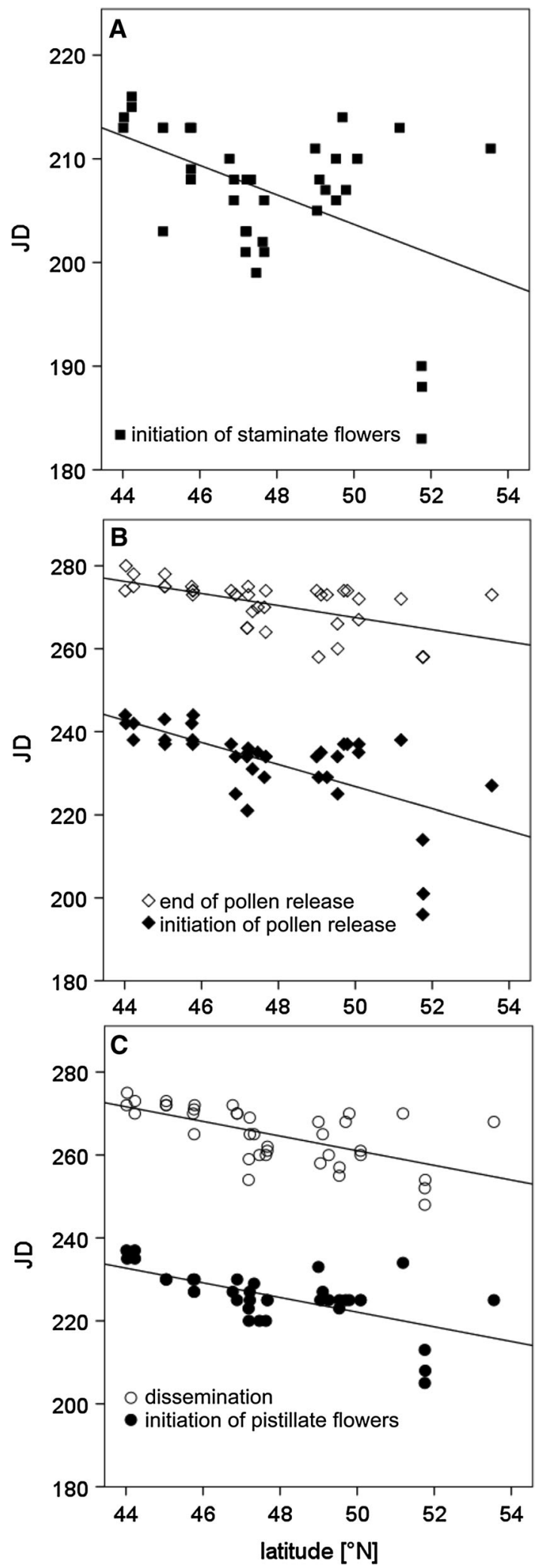

4 Fig. 4 Floral development of A. artemisiifolia populations in relation to their geographical origin. a Initiation of staminate flowers (Spearman $\rho=-0.403, P=0.01$ ). b Initiation (Spearman $\rho=-0.633, P<0.001$ ) and end (Spearman $\rho=-0.660$, $P<0.001)$ of pollen release. c Initiation of pistillate flowers (Spearman $\rho=-0.661, P<0.001$ ) and dissemination (Spear$\operatorname{man} \rho=-0.699, P<0.001)$. JD = Julian day, $\mathrm{N}=38$

history traits, e.g. germination traits, no correlations with environmental factors have been found, despite a high level of variation between populations for these traits (Leiblein-Wild et al. 2013). Most of the differences between populations observed in this study were correlated with environmental parameters and/or the geographical origin. For different developmental stages (early growth, late growth and flowering phenology) different relationships were found which are discussed in the following.

Phenotypic variation of early and late growth

Early growth $\left(\mathrm{AGR}_{\mathrm{Jun}}, \mathrm{AGR}_{\mathrm{Jul}}\right)$ was significantly higher in agricultural populations than in ruderal populations. Possibly, individuals originating from agricultural sites may benefit from maternal effects due to increased fertilization at these sites. Maternal effects may influence the performance of the offspring resulting in an advanced early growth of the offspring (Mousseau and Fox 1998; Räsänen and Kruuk 2007; Roach and Wulff 1987). However seed mass — which can be a direct cue of high investment in the offspring and which increases with increased nutrient supply (reviewed in Roach and Wulff 1987)—did not differ between ruderal and agricultural populations. Late growth, $\mathrm{AGR}_{\mathrm{Aug}}$ and the maximal biomass values $\left(\mathrm{ABM}_{\mathrm{Max}}\right)$ did not differ between populations from agricultural and ruderal sites, suggesting that possible maternal effects mainly affect early developmental stages in A. artemisiifolia. Maternal effects may have a substantial influence on an individual's phenotype at the early seedling stage, but often these effects diminish over time (Mousseau and Fox 1998; Roach and Wulff 1987).

Correlation of early and late growth with environmental parameters

For ruderal populations, early growth $\left(\mathrm{AGR}_{\mathrm{Jun}}\right.$ and $\mathrm{AGR}_{\mathrm{Jul}}$, measured under 'optimal' moisture conditions) was negatively correlated with precipitation, i.e. 
individuals originating from drier regions achieved higher biomass than ones from moister regions. We therefore hypothesize a possible selection to different precipitation conditions. A. artemisiifolia is able to adapt actively to different soil moisture conditions (Leiblein and Lösch 2011). Thus, individuals from dry habitats might have properties which allow them to survive even at low precipitation levels. At our experimental site, where moisture was good, these individuals might have been able to use the water resources more efficiently which is especially important for early developmental stages. Accordingly, no correlation was found between late growth ( $\left.\mathrm{AGR}_{\text {Aug }}\right)$ and precipitation. For agricultural populations, no correlation of $\mathrm{AGR}_{\mathrm{Jun}}$ and $\mathrm{AGR}_{\mathrm{Jul}}$ with precipitation at the sites of origin was found. However, in southern Europe agricultural sites are often irrigated and therefore the precipitation data of the WorldClim Database might be less appropriate to describe the environmental conditions at these sites.

For late growth, variation in $\mathrm{AGR}_{\text {Aug }}$ and $\mathrm{ABM}_{\mathrm{Max}}$ was correlated with latitude, respectively LOD: Individuals from northern regions remained smaller than those originating from lower latitude sites. This finding is consistent with observations from Dickerson and Sweet (1971) who demonstrated the same phenomena in the native range of common ragweed. They found an even stronger correlation between biomass and the latitudinal origin (Spearman $\rho=$ $-0.95, P<0.001$, ESM Fig. A3), but their observations covered a latitudinal gradient from $27^{\circ} \mathrm{N}$ to $46^{\circ} \mathrm{N}$, whereas our experiments only cover a range from $44^{\circ} \mathrm{N}$ to $54^{\circ} \mathrm{N}$. But even when considering only a similar latitudinal gradient of around $10^{\circ}\left(37^{\circ} \mathrm{N}-\right.$ $46^{\circ} \mathrm{N}$ ) the correlation for North American populations remains stronger (Spearman $\rho=-0.936$, $P<0.001)$ than the one we observed for the European ones. One reason for this might be found in the invasion history of $A$. artemisiifolia. Since the species is relatively new in Europe, adaptations to environmental conditions may be not that strong yet as in the native range. Furthermore, the income of seed material from distinct sources, which is known for A. artemsiifolia in Europe (Genton et al. 2005b), may enhance genotypic variability at the points of origin and attenuate local adaptation to environmental conditions.

$\mathrm{ABM}_{\text {Max }}$ was very positively correlated with temperature, i.e. populations originating from warmer regions achieved the highest biomass. The temperature conditions at the experimental site were ca. $2{ }^{\circ} \mathrm{C}$ warmer during the experiment than the mean temperature for 1950-2000, and thus more typical for temperature conditions in the centre or the south of common ragweed's current distribution in Europe. Therefore, individuals from middle and southern sites grew under conditions they also would have received on average at their original site. If an adaptation to temperature prevailing at these sites exists, these individuals might have had an advantage leading to the increased biomass that we observed in our experiment. Alternatively, benefits from maternal effects of populations from warmer provenances could explain the increased biomass.

Phenotypic variation in flowering phenology and correlation with environmental parameters

We found great differences for all floral dates between the populations. As we hypothesized, flowering phenology did not differ between populations from ruderal and agricultural sites. Furthermore, we found no correlation of flowering dates with precipitation prevailing at the points of origin. Instead, the floral development of A. artemisiifolia was highly correlated with latitude, respectively LOD, and longitude. The LOD at which the initiation of male flowering occurred varied from $16.30 \mathrm{~h}$ (at JD 183 for Pop 32) to $15.08 \mathrm{~h}$ (at JD 216 for Pop 15) between the European populations. We therefore consider that European populations might be adapted to a specific LOD prevailing at their respective sites of origin. This means each population would start flowering as soon as a certain value of LOD arrives. For example, the LOD given in July in the Brandenburgian region (pops. 31-33) occurs in Frankfurt around 4 weeks earlier. In consequence, populations adapted to the Brandenburgian LOD would flower earlier under Frankfurt LOD conditions, as we observed in our experiment. Genton et al. (2005a) found similarities in the flowering phenology of French and Canadian populations: transplanted individuals from northern regions flowered earlier than ones from the south. These authors also suggest either an adaptation to a similar photoperiod in similar latitudes or a common origin from similar latitudes. For the native range a similar latitudinal gradient has been described by Dickerson and Sweet (1971). 
All floral dates were highly correlated with longitude. A longitudinal gradient in flowering phenology has not yet been described for A. artemisiifolia. Samis et al. (2008) described a longitudinal gradient in the onset of flowering in Arabidopsis thaliana with eastern populations flowering earlier. Menzel et al. (2005) suggest that longitudinal variation is at least as significant as latitudinal variation for determining seasonal onset in many plant species. It may result from the climatic effects of continentality, which is characterized by varying climatic effects of oceanic current oscillations between coastal and continental sites. As autumn arrives earlier in Eastern than in Western Europe (Menzel et al. 2005), starting the reproductive stage earlier may be crucial to fulfill the life cycle, especially in annual plant species such as common ragweed. Our findings for the male flowering phases support the above mentioned assumption. Surprisingly, we found converse correlations for female floral dates, since the eastern populations had later floral dates.

Regarding temperature, we found that pollen release, initiation of pistillate flowers, and dissemination were correlated with temperature, while the onset of staminate flowering and length of pollen release were not. We suggest that a local adaptation to temperature conditions prevailing at the point of origin may exist for the first mentioned developmental stages.

The length of pollen release was not correlated with any environmental variable except for a weak correlation with longitude. However, the length of pollen release varied considerably between the populations so that it may be either genetically fixed or related with factors other than the factors we investigated in our study.

Possible origin of the local adaptation of European common ragweed populations

Genetically determined clines in plant traits along latitudinal gradients between populations of other introduced species have been observed (Alexander and Edwards 2010). Such genetic variation may arise after introduction as an evolutionary response to altered environmental conditions, or due to a survival of best adapted genotypes at each provenance. Evolutionary responses may occur within less than 20 generations (Prentis et al. 2008; Whitney and Gabler
2008). Especially in plants with a short generation time (Jump and Penuelas 2005) this can happen within a short time-span. As common ragweed solely reproduces sexually and is strongly self-incompatible (Friedman and Barrett 2008) it should be able to evolve rapidly.

Additionally, the observed variation may rely on the survival of best adapted genotypes at each site. This also seems reasonable enough for A. artemisiifolia, since the species' presence in Europe is the result of several introduction events (Genton et al. 2005b). For example, French A. artemisiifolia populations are genetically highly diverse due to repeated introduction events from North America (Genton et al. 2005b). Furthermore, some authors argue that flowering phenology of alien species is a genetically determined trait that is modified very little when a species is invading a new region (Godoy et al. 2009), which contradicts the assumption of an adaptive response in floral development after introduction.

From our experiment we cannot distinguish between variation due to genetic differentiation as evolutionary response and variation due to the survival of best genotypes. To clarify this question, comparative genetic studies analyzing North American and European A. artemisiifolia populations over a big spatial gradient are needed. As the absolute values for phenotypic variation and their correlation with environmental conditions are derived from a 1 yearexperiment, future studies of selection are required to confirm our findings.

Acknowledgments The present study was conducted at the Biodiversity and Climate Research Centre (BiK-F), Frankfurt am Main, and funded by the research funding programme 'LOEWE-Landes-Offensive zur Entwicklung wissenschaftlich-ökonomischer Exzellenz' of Hesse's Ministry of Higher Education, Research, and the Arts. We cordially thank Sarah Cunze for providing the climatic data, Cornelia Bäucker, Felix Heydel, Ulf Schmitz and Thomas Breuning for contributing seed material, Martin Kalbfuß and Manuel Sommer for the help during the common garden experiment, and the botanical garden of the Goethe University Frankfurt for supporting the experiment. We furthermore thank Rainer Lösch and four anonymous reviewers for their helpful comments on earlier versions of this manuscript, and Daniel Grobbel-Rank for improving the English.

Open Access This article is distributed under the terms of the Creative Commons Attribution License which permits any use, distribution, and reproduction in any medium, provided the original author(s) and the source are credited. 


\section{References}

Alberternst B, Nawrath S, Klingenstein F (2006) Biologie, Verbreitung und Einschleppungswege von Ambrosia artemisiifolia in Deutschland und Bewertung aus Naturschutzsicht. Nachrbl Dtsch Pflanzenschutzd 58:1-7

Alexander JM, Edwards PJ (2010) Limits to the niche and range margins of alien species. Oikos 119:1377-1386

Allard HA (1945) Flowering behavior and natural distribution of the eastern ragweed (Ambrosia) as affected by length of day. Ecology 26:387-394

Bassett IJ, Crompton CW (1975) The biology of Canadian weeds. 11. Ambrosia artemisiifolia L. and A. psilostachya DC. Can J Plant Sci 55:463-476

$\mathrm{BBCH}$, Monograph (eds) (2001) Growth stages of mono- and dicotyledonous plants, 2nd edn. Federal Biological Research Centre for Agriculture and Forestry

Becker U, Colling G, Dostal P, Jakobsson A, Matthies D (2006) Local adaptation in the monocarpic perennial Carlina vulgaris at different spatial scales across Europe. Oecologia 150:506-518

Bradshaw WE, Zani PA, Holzapfel CM (2004) Adaptation to temperate climates. Evolution 58:1748-1762

Brandes D, Nitzsche J (2006) Biology, introduction, dispersal, and distribution of common ragweed (Ambrosia artemisiifolia L.) with special regard to Germany. Nachrbl Dtsch Pflanzenschutzd 58:286-291

Bruelheide H, Heinemeyer A (2002) Climatic factors controlling the eastern and altitudinal distribution boundary of Digitalis purpurea L. in Germany. Flora 197:475-490

Chun YJ, Le Corre V, Bretagnolle F (2011) Adaptive divergence for a fitness-related trait among invasive Ambrosia artemisiifolia populations in France. Mol Ecol 20:1378-1388

Cunze S, Leiblein MC, Tackenberg O (2013) Range expansion of Ambrosia artemisiifolia in Europe is promoted by climate change. ISRN Ecol vol 2013, Article ID 610126. doi:10.1155/2013/610126

Dickerson CT, Sweet RD (1971) Common ragweed ecotypes. Weed Sci 19:64-66

Dlugosch KM, Parker IM (2008) Invading populations of an ornamental shrub show rapid life history evolution despite genetic bottlenecks. Ecol Lett 11:701-709

Erfmeier A, Böhnke M, Bruelheide H (2013) Secondary invasion of Acer negundo: the role of phenotypic responses versus local adaptation. Biol Invasions 13:1599-1614

Friedman J, Barrett SC (2008) High outcrossing in the annual colonizing species Ambrosia artemisiifolia (Asteraceae). Ann Bot 101:1303-1309

Fumanal B (2007) Caractérisation des traits biologiques et des processus évolutifs d'une espèce envahissante en France: Ambrosia artemisiifolia L. In Université de Bourgogne, Dijon

Fumanal B, Chauvel B, Sabatier A, Bretagnolle F (2007) Variability and cryptic heteromorphism of Ambrosia artemisiifolia seeds: what consequences for its invasion in France? Ann Bot 100:305-313

Genton BJ, Kotanen PM, Cheptou PO, Adolphe C, Shykoff JA (2005a) Enemy release but no evolutionary loss of defence in a plant invasion: an inter-continental reciprocal transplant experiment. Oecologia 146:404-414
Genton BJ, Shykoff JA, Giraud T (2005b) High genetic diversity in French invasive populations of common ragweed, Ambrosia artemisiifolia, as a result of multiple sources of introduction. Mol Ecol 14:4275-4285

Godoy O, Castro-Díez P, Valladares F, Costa-Tenorio M (2009) Different flowering phenology of alien invasive species in Spain: evidence for the use of an empty temporal niche? Plant Biol 11:803-811

Hierro JL et al (2009) Germination responses of an invasive species in native and non-native ranges. Oikos 118:529-538

Hijmans RJ, Cameron SE, Parra JL, Jones PG, Jarvis A (2005) Very high resolution interpolated climate surfaces for global land areas. Int J Climatol 25:1965-1978

Hodgins KA, Rieseberg L (2011) Genetic differentiation in lifehistory traits of introduced and native common ragweed (Ambrosia artemisiifolia) populations. J Evol Biol 24:2731-2749

Joshi J et al (2001) Local adaptation enhances performance of common plant species. Ecol Lett 4:536-544

Jump SA, Penuelas J (2005) Running to stand still: adaptation and the response of plants to rapid climate change. Ecol Lett 8:1010-1020

Kazinczi G, Béres I, Pathy Z, Novák R (2008) Common ragweed (Ambrosia artemisiifolia): a review with special regards to the results in Hungary. II. Importance and harmful effect, allergy, habitat, allelopathy and beneficial characteristics. Herbologia 9:93-118

Kollmann J, Banuelos MJ (2004) Latitudinal trends in growth and phenology of the invasive alien plant Impatiens glandulifera (Balsamiaceae). Divers Distrib 10:377-384

Lee CE (2002) Evolutionary genetics of invasive species. Trends Ecol Evol 17:386-391

Leiblein MC, Lösch R (2011) Biomass development and $\mathrm{CO}_{2}$ gas exchange of Ambrosia artemisiifolia $\mathrm{L}$. under different soil moisture conditions. Flora 206:511-516

Leiblein-Wild MC, Kaviani R, Tackenberg O (2013) Germination and seedling frost tolerance differ between the native and invasive range in common ragweed. Oecologia. doi:10.1007/s00442-013-2813-6

Leskovsek R, Eler K, Batic F, Simoncic A (2012) The influence of nitrogen, water and competition on the vegetative and reproductive growth of common ragweed (Ambrosia artemisiifolia L.). Plant Ecol 213:769-781

Menzel A, Sparks TH, Estrella N, Eckhardt S (2005) 'SSW to NNE'-North Atlantic Oscillation affects the progress of seasons across Europe. Glob Change Biol 11:909-918

Montague JL, Barrett SCH, Eckert CG (2008) Re-establishment of clinal variation in flowering time among introduced populations of purple loosestrife (Lythrum salicaria, Lythraceae). J Evol Biol 21:234-245

Mousseau TA, Fox CW (1998) The adaptive significance of maternal effects. Trends Ecol Evol 13:403-407

Otto C, Alberternst B, Klingenstein F, Nawrath S (2008) Verbreitung der Beifußblättrigen Ambrosie in Deutschland. Problematik und Handlungsoptionen aus Naturschutzsicht, BfN-Skripten 235

Paquin V, Aarssen LW (2004) Allometric gender allocation in Ambrosia artemisiifolia (Asteraceae) has adaptive plasticity. Am J Bot 91:430-438 
Parker IM, Rodriguez J, Loik ME (2003) An evolutionary approach to understanding the biology of invasions: local adaptation and general-purpose genotypes in the weed Verbascum thapsus. Conserv Biol 17:59-72

Prentis PJ, Wilson JRU, Dormontt EE, Richardson DM, Lowe AJ (2008) Adaptive evolution in invasive species. Trends Plant Sci 13:288-294

Räsänen K, Kruuk LEB (2007) Maternal effects and evolution at ecological time-scales. Funct Ecol 21:408-421

Reznik SY (2009) Common Ragweed (Ambrosia artemisiifolia L.) in Russia: spread, distribution, abundance, harmfulness and control measures, Ambroisie. First Int Ragweed Rev 26:88-97

Richards CL, Bossdorf O, Muth NZ, Gurevitch J, Pigliucci M (2006) Jack of all trades, master of some? On the role of phenotypic plasticity in plant invasions. Ecol Lett 9:981-993

Roach DA, Wulff RD (1987) Maternal effects in plants. Annu Rev Ecol Syst 18:209-235

Saikkonen K et al (2012) Climate change-driven species' range shifts filtered by photoperiodism. Nat Clim Change 2:239-242

Samis KE, Heath KD, Stinchcombe JR (2008) Discordant longitudinal clines in flowering time and phytochrome $\mathrm{C}$ in Arabidopsis thaliana. Evolution 62:2971-2983

Tackenberg O (2007) A new method for non-destructive measurement of biomass, growth rates, vertical biomass distribution and dry matter content based on digital image analysis. Ann Bot 99:777-783

Taramarcaz P, Lambelet B, Clot B, Keimer C, Hauser C (2005) Ragweed (Ambrosia) progression and its health risks: will Switzerland resist this invasion? Swiss Med Wkly 135:538-548

Thomas B, Vince-Prue D (1997) Photoperiodism in plants. Academic Press, New York

Toole EH, Brown E (1946) Final results of the Durvel buried seed experiment. J Agric Res 72:201-210

Van Dijk H, Hautekèete N (2007) Long day plants and the response to global warming: rapid evolutionary change in day length sensitivity is possible in wild beet. J Evol Biol 20:349-357

Weber E, Schmid B (1998) Latitudinal population differentiation in two species of Solidago (Asteraceae) introduced into Europe. Am J Bot 85:1110-1121

Whitney KD, Gabler CA (2008) Rapid evolution in introduced species, 'invasive traits' and recipient communities: challenges for predicting invasive potential. Divers Distrib 14:569-580

Willemsen RW (1975) Effect of stratification temperature and germination temperature on germination and the induction of secondary dormancy in common ragweed seeds. Am J Bot 62:1-5 